\title{
The Amino Acid Requirements of a Single Strain of Actinomyces israelii Growing in a Chemically Defined Medium
}

\author{
By H. A. KEIR and J. W. POR'TEOUS \\ Department of Biological Chemistry, Marischal College, University of Aberdeen
}

(Received 1 May 1961)

\begin{abstract}
SUMMARY
The Wills strain of Actinomyces israelii will survive repeated subculture in the medium HP 9 described by Christie \& Porteous (1962 $b$ ) but modified to contain ammonium sulphate and only seven amino acids (serine, cysteine, glutamic acid, lysine, leucine, isoleucine and tryptophan); the total $-\mathrm{N}$ content of this new medium was $240 \mu \mathrm{g} . / \mathrm{ml}$. On the evidence available this new medium probably represents the minimal medium in respect of amino acids (and growth factors) for this strain of Actinomyces israelii. The yield of organism from this new medium was comparable with that reported by Christie \& Porteous (1962a) for more complex media, namely approximately $70 \mu \mathrm{g}$. cell total- $\mathrm{N} / \mathrm{ml}$. medium. Some observations are presented on inhibition of growth of Actinomyces israelii by 'growth factors' and by purine and pyrimidine bases.
\end{abstract}

\section{INTRODUCTION}

Christie \& Porteous (1962a) described a medium HP6/B, referred to hereafter as medium CP1 (Table 1). This medium contained $613 \mu \mathrm{g}$. total-N/ml. and sustained the Wills strain of Actinomyces israelii in repeated anaerobic subculture with a yield of organism equivalent to $70 \mu \mathrm{g}$. total- $\mathrm{N} / \mathrm{ml}$. medium. L-Cysteine and L-tryptophan were shown to be essential nutrients of this single strain of $A$. israelii when grown in the presence of all sixteen growth factors of medium CP1 (Table 1). In semiquantitative experiments it was shown (Christie \& Porteous, 1962 $b$ ) that of the sixteen growth factors present in medium CP1, only five were essential for the growth of this strain of $A$. israelii. Medium CP1 modified to contain these five growth factors is referred to hereafter as medium CP 2 (Table 1). These semiquantitative experiments have now been put on to a quantitative basis. It has also been shown that only seven of the amino acids of medium CP 2 are required to sustain the Wills strain through at least ten serial cultures, when the medium is supplemented with ammonium sulphate.

\section{METHODS}

With the following exceptions and additions, the materials and techniques used in the present work were those described by Christie \& Porteous (1960, 1962 $a, b)$.

Organism. The Wills strain of Actinomyces israelii (Christie \& Porteous, 1962a) was used.

Media and analytical solutions. These were made up in de-ionized water; all amino acids were the L-isomers. 
Preparation of inoculum suspensions of Actinomyces israelii, and quantitative inoculation of experimental media. The technique described by Christie \& Porteous (1960) was used with slight modifications: (i) a chemically defined medium was used in both stages of the stirred culture method of preparing inoculum suspensions; (ii) the colonies were harvested from the first stage culture when the medium

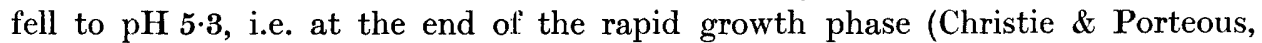
$1962 a)$; (iii) these harvested colonies were washed aseptically with $3 \times 10 \mathrm{ml}$. volumes of sterile distilled water before being transferred to the second stage medium; (iv) when the $\mathrm{pH}$ of the second stage medium fell to a value of $5 \cdot 3$ colonies were again harvested and washed as before. Quantitative inoculation of this final suspension of colonies into experimental media was carried out as described by Christie \& Porteous (1960).

$\alpha$-Amino-nitrogen determinations. These were carried out by the method of Yemm \& Cocking (1955).

Amino acid chromatography. Zeo-Karb 225 ion-exchange columns $(5 \cdot 0 \mathrm{~cm} . \times$ $0.8 \mathrm{~cm}$.) were freshly converted to the $\mathrm{H}$-ion form and washed with de-ionized water in the usual way; a measured volume of medium (3-5 ml.) was added to the column and inorganic salts eluted with de-ionized water. The amino acids were eluted with N-ammonia; elution was continued until tests with microlitre volumes of eluate spotted on to filter paper and dried in a current of warm air showed that no more ninhydrin-positive material was leaving the column. The complete ammonia eluate was shell-frozen in solid carbon dioxide + ethanol mixture and dried from the frozen state ir vacuo $(0.1 \mathrm{~mm} . \mathrm{Hg})$ over solid $\mathrm{KOH}$ and conc. $\mathrm{H}_{2} \mathrm{SO}_{4}$. The solid residue was dissolved in $500 \mu \mathrm{l}$. de-ionized water. Control experiments showed that this procedure removed ammonia from the eluate thus permitting determination of the recovery of $\alpha$-amino-N in the eluate (Kornberg \& Patey, 1957). The shell-freezing and drying technique permitted convenient concentration of amino acid solutions before application of a known volume (usually $15 \mu \mathrm{l}$.) containing 50-75 $\mu$-g. total $\alpha$-amino-N to paper chromatograms.

The solvents used for descending two-dimensional chromatography by the technique of Levvy \& Chung (1953) were: $n$-butanol + acetic acid + water $(4+1+5$ vol.) followed by phenol $+m$-cresol $+0.06 \mathrm{M}$-borate buffer $(\mathrm{pH} \mathrm{9.3)}(25 \mathrm{~g} .+25 \mathrm{~g} .+$ $7 \mathrm{ml}$.). This solvent pair gave excellent separation, on $46 \mathrm{~cm} . \times 56 \mathrm{~cm}$. sheets of Whatman no. 1 chromatography paper, of all amino acids ('Table 1) except methionine, valine, leucine, isoleucine, phenylalanine and tryptophan which formed an overlapping group of three large ninhydrin-positive spots in the corner of the chromatograms diametrically opposite the starting point. The area of paper containing these six amino acids was dried at $40^{\circ}$, cut into strips and the amino acids eluted according to the method of Dent(1947). The combined eluates were ether extracted to remove traces of phenol and $m$-cresol, desalted to remove any borate eluted from the previous chromatograms, then shell-frozen as described. The dry residue was dissolved in $50 \mu \mathrm{l}$. de-ionized water before application of the whole solution to a further sheet of Whatman no. 1 chromatography paper, $23 \mathrm{~cm} . \times 28 \mathrm{~cm}$. The solvents used for ascending two-dimensional chromatography were: tertbutanol + methylethylketone + water $(4+4+2$ vol. $)$ followed by tert-butanol + methanol + water $(4+5+1$ vol.) as described by Boissonas (1950).

For qualitative detection of amino acids the chromatograms were sprayed with 
$0.1 \%(\mathrm{w} / \mathrm{v})$ ninhydrin in water-saturated $n$-butanol (Consden, Gordon \& Martin, 1944) to which $1 \%(\mathrm{v} / \mathrm{v}) 2: 4: 6$-collidine had been added; the sprayed chromatograms were heated at $80^{\circ}$ for 5-10 min. For quantitative work the amino acids were located by the ultraviolet irradiation technique of Fowden (1951), then eluted according to the method of Kornberg \& Patey (1957) and determined by the method of Yemm \& Cocking (1955).

\section{RESULTS}

Amino acid assimilation by a culture of Actinomyces israelii. A rapidly growing culture of the Wills strain in medium CP1 was harvested and washed aseptically with sterile distilled water $(3 \times 10 \mathrm{ml}$.). The suspension of organisms was used to prepare an inoculum in medium CP1 by the culture technique described under Methods. The final suspension provided a massive inoculum for an experimental flask containing about $100 \mathrm{ml}$. medium CPl sealed with liquid paraffin. This flask, together with a similar flask of uninoculated medium, was incubated at $37^{\circ}$.

Initially the medium was at $\mathrm{pH} 7 \cdot 2$. The $\mathrm{pH}$ value of the medium was measured

Table 1. The composition of medium $\mathrm{CP} 1$ and of medium $\mathrm{CP}_{2}$

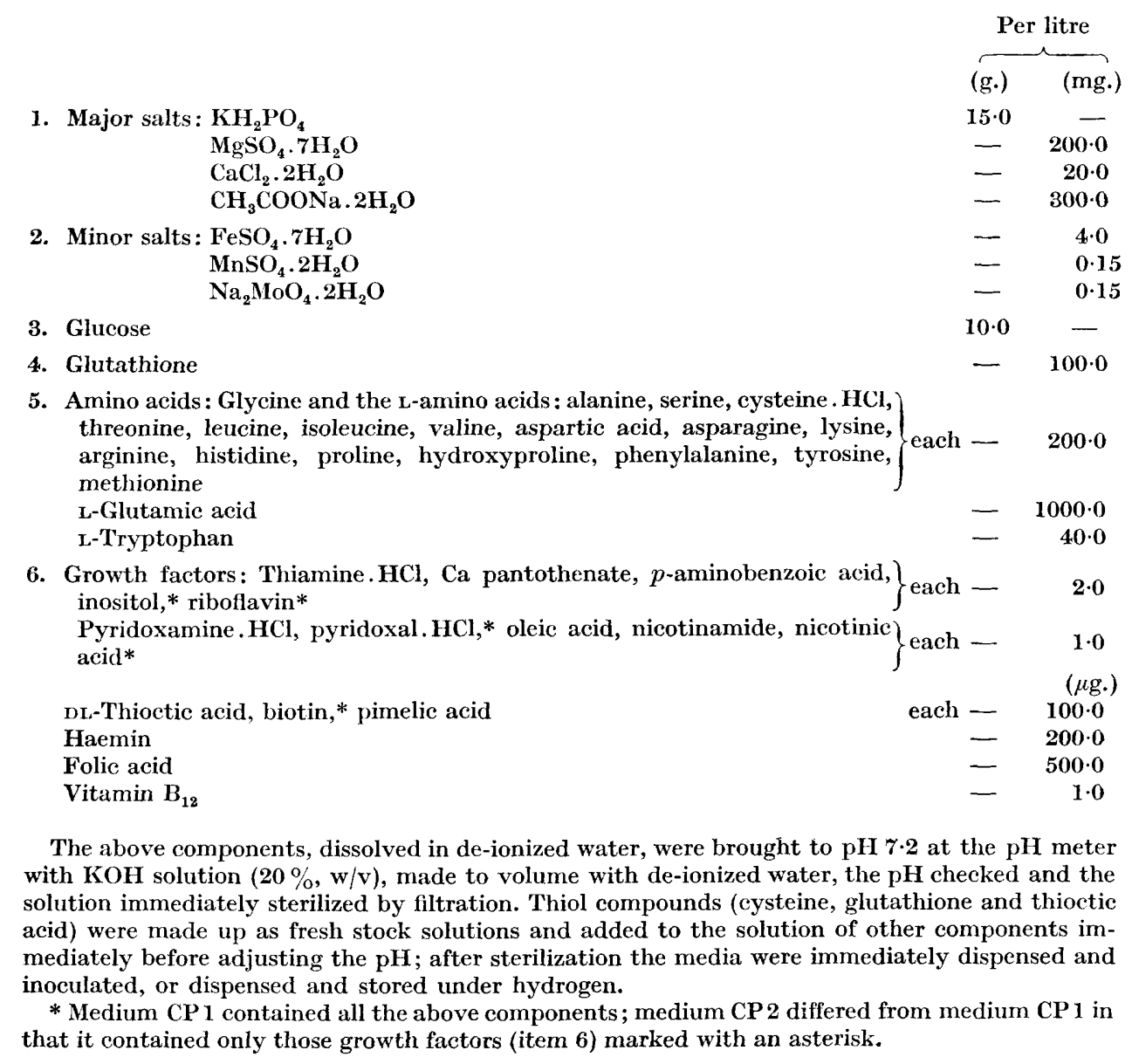


twice daily and the colonies har ested when the $\mathrm{pH}$ of the medium reached a value of 5.3, at which point the culture was about to enter the stationary phase. A sample of the early stationary phase medium was filtered through Whatman no. 1 filter paper to remove traces of liquid paraffin, sterilized by filtration through a cellulose acetate membrane (Christie \& Porteous, $1962 a$ ) and subjected, along with a similarly treated sample of uninocilated medium, to chromatographic analysis for amino acids. The results obtained are shown in Table $2 ; 101 \mu \mathrm{g} . \alpha$-amino-N were removed from each millimetre of medium during 6 days of growth. Most of this net decrease in the $\alpha$-amino- $\mathbf{N}$ was accounted for by a decrease in the concentrations of serine, cysteine, glutamic acid, Iysine and (leucine +isoleucine), which together accounted for a decrease of $86 \mu \mathrm{g} . \alpha$-amino-N/ml. medium. Tryptophan, which was

Table 2. Changes in the amino acid composition of medium CP1 (Table 1) after 6 days of growth of the Wills strain of Act nomyces israelii at $37^{\circ}$ under liquid paraffin seal

\begin{tabular}{|c|c|c|c|c|c|c|c|}
\hline Amino acid & $\begin{array}{c}0 \\
\text { (days) }\end{array}$ & $\begin{array}{c}0 \\
\text { (days) }\end{array}$ & $\begin{array}{c}6 \\
\text { (days) }\end{array}$ & $\begin{array}{c}0 \\
\text { (days) }\end{array}$ & $\begin{array}{c}6 \\
\text { (days) }\end{array}$ & $\begin{array}{c}\text { or } \\
\text { decrease }\end{array}$ & $\begin{array}{c}\text { or } \\
\text { decrease }\end{array}$ \\
\hline Glycine & $37 \cdot 3$ & $34 \cdot 8$ & $39 \cdot 2$ & 186 & 210 & +24 & $+12 \cdot 9$ \\
\hline Alanine & $31 \cdot 4$ & $29 \cdot 9$ & $23 \cdot 6$ & 190 & 150 & -40 & $-21 \cdot 1$ \\
\hline Serine & $26 \cdot 6$ & $22 \cdot 3$ & $11 \cdot 1$ & 167 & 83 & -84 & $-50 \cdot 3$ \\
\hline Cysteine. $\mathrm{HCl}$ & $17 \cdot 9$ & $25 \cdot 9$ & $11 \cdot 1$ & 292 & 125 & -167 & $-57 \cdot 2$ \\
\hline Threonine & $23 \cdot 5$ & $23 \cdot 2$ & $28 \cdot 1$ & 197 & 238 & +41 & $+20 \cdot 8$ \\
\hline Methionine & $18 \cdot 8$ & $20 \cdot 1$ & $15 \cdot 6$ & 213 & 166 & -47 & $-22 \cdot 1$ \\
\hline Aspartic acid & $21 \cdot 0$ & $20 \cdot 1$ & $17 \cdot 8$ & 190 & 169 & -21 & $-11 \cdot 1$ \\
\hline Asparagine & $21 \cdot 2$ & $22 \cdot 3$ & $22 \cdot 3$ & 210 & 210 & 0 & 0 \\
\hline Glutamic acid & $95 \cdot 2$ & $85 \cdot 0$ & $49 \cdot 0$ & 897 & 516 & -381 & $-42 \cdot 4$ \\
\hline Lysine & $19 \cdot 2$ & $22 \cdot 8$ & $11 \cdot 1$ & 238 & 116 & -122 & $-51 \cdot 3$ \\
\hline Arginine & $16 \cdot 0$ & $17 \cdot 3$ & $14 \cdot 8$ & 215 & 184 & -31 & $-14 \cdot 4$ \\
\hline Histidine & $18 \cdot 1$ & $19 \cdot 8$ & $19 \cdot 4$ & 219 & 214 & -5 & $-2 \cdot 3$ \\
\hline Valine & $23 \cdot 9$ & $22 \cdot 3$ & $25 \cdot 9$ & 186 & 216 & +30 & $+16 \cdot 1$ \\
\hline Leucine/isoleucine & $42 \cdot 6$ & $40 \cdot 6$ & $28 \cdot 1$ & 379 & 262 & -117 & $-30 \cdot 9$ \\
\hline Proline & $24 \cdot 3$ & $22 \cdot 3$ & $22 \cdot 3$ & 183 & 183 & 0 & 0 \\
\hline Hydroxyproline & $21 \cdot 4$ & $23 \cdot 6$ & $17 \cdot 8$ & 221 & 167 & -54 & $-24 \cdot 4$ \\
\hline Phenylalanine & $16 \cdot 9$ & $13 \cdot 4$ & $9 \cdot 8$ & 157 & 115 & -42 & $-26 \cdot 7$ \\
\hline Tyrosine & $15 \cdot 5$ & $13 \cdot 4$ & $10 \cdot 7$ & 173 & 138 & -35 & $-20 \cdot 2$ \\
\hline Tryptophan & $2 \cdot 7$ & - & - & - & 一 & - & - \\
\hline Totals & $493 \cdot 5$ & $479 \cdot 1$ & $377 \cdot 7$ & 一 & - & 一 & - \\
\hline$\%$ calculated value & - & 17 & - & - & 一 & 一 & - \\
\hline Net decrease & - & - & $101 \cdot 4$ & - & - & 一 & - \\
\hline
\end{tabular}

present initially at a much lower concentration than the other amino acids, was not estimated in this experiment, but Christie \& Porteous (1962a) showed that tryptophan (and cysteine) were essential nutrients for this strain of Actinomyces israelii. Christie (unpublished) obtained some growth of the Wills strain of $A$. israelii in medium CP1, modified to contain only the seven L-amino acids serine, cysteine, glutamic acid, lysine, leucine, isoleucine and tryptophan, but the organism did not survive more than a few subcultures in this medium. The results shown in Table 2 , together with the work of Christie \& Porteous (1962 $a$ ), nevertheless suggested that 
these seven amino acids belonged to a group which was preferentially removed by the Wills strain from a complete amino acid medium. It was therefore decided to determine the growth curves for the Wills strain in six different media based on medium CP1 and on medium CP2. These six media are listed in Table 3.

\section{Table 3. The composition of six test media based on medium $C P 1$ and on medium CP2 (Table 1)}

$\left(\mathrm{NH}_{4}\right)_{2} \mathrm{SO}_{4}$ added at a concentration of $200 \mu \mathrm{g} . / \mathrm{ml}$. and the purines and pyrimidines (adenine sulphate, guanine hydrochloride dihydrate, uracil, xanthine and thymine) each at a concentration of $20 \mu \mathrm{g}$./ml. (Christie \& Porteous, 1962a).

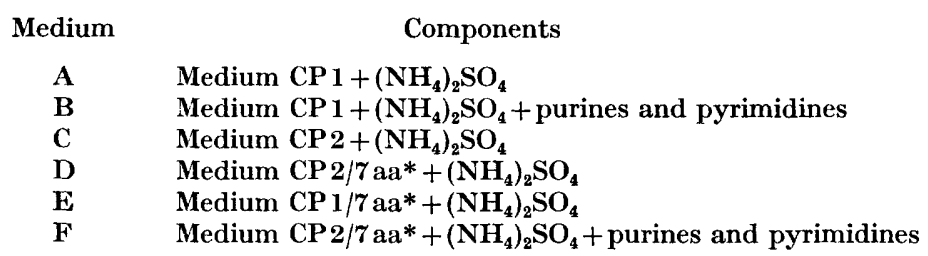

* Medium CP1 or medium CP2 modified to contain only seven L-amino acids (serine, cysteine, leucine, isoleucine, lysine, glutamic acid and tryptophan) at the concentrations given in Table 1.

Table 4. The yield of organism obtained from the stationary phase of cultures of the Wills strain of Actinomyces israelii in seven defined media (Table 3)

All cultures entered the stationary phase after about $200 \mathrm{hr}$. incubation; the approximate lag periods were: media $B$ and C, $60 \mathrm{hr}$; media $A$ and D, $70 \mathrm{hr}$.; $\mathrm{E}$ and F, $100 \mathrm{hr}$. Conditions of incubation are given in the text.

$\begin{array}{cc}\text { Medium } & \begin{array}{c}\text { Yield of organism in } \\ \text { stationary phase }\end{array} \\ \text { A } & \text { ( } \mathrm{g} \text {. total-N/ml. medium }) \\ \text { B } & 80 \\ \text { C } & 80 \\ \text { D } & 70 \\ \text { E } & 70 \\ \text { F } & 40 \\ \text { CP2 } & 42 \\ & 70\end{array}$

Growth of the Wills strain of Actinomyces israelii in modified media. Medium B was used in the first and second stages of the modified culture technique of Christie \& Porteous (1960) described under Methods. The final washed suspension was used for uniform quantitative inoculation of replicate paraffin-sealed tubes of each of seven test media. The results obtained are shown in Table 4.

Media A, B, C, D and CP2 (Tables 1 and 3) gave good yields of Actinomyces israelii, comparable with those reported by Christie \& Porteous (1962a), and growth rates in the four media were very similar. Medium D was the simplest medium, containing only seven amino acids and five growth factors (Tables 1 and $\mathbf{3}$ ). Poor yields and growth rates were obtained in media $\mathbf{E}$ and $\mathbf{F}$.

At the conclusion of this experiment colonies were subcultured from medium $\mathbf{D}$ into tubes of fresh medium D; subcultures were made at 5-day intervals thereafter until the growing colonies had passed through seven serial cultures in this medium. Colonies from twelve tubes each containing $2 \mathrm{ml}$. medium $\mathrm{D}$ were then harvested, 
washed as previously described and taken through the first and second stages of the culture technique of Christie \& Porteous (1960), using medium D and the slight modifications to the technique already described under Methods, except that the $\mathrm{pH}$ value of the second-stage medium was allowed to fall to $\mathrm{pH} \mathbf{5 \cdot 5}$. The two stages of this culture technique constituted the eighth and ninth serial passage of the growing colonies through medium D. The harvested and washed colonies from the ninth culture were used to provide uniform inocula (Christie \& Porteous, 1960) for replicate tubes each containing $2 \mathrm{ml}$. medium $\mathrm{D}$. The growth curve obtained in this tenth serial culture in medium $\mathbf{D}$ is shown in Fig. 1.

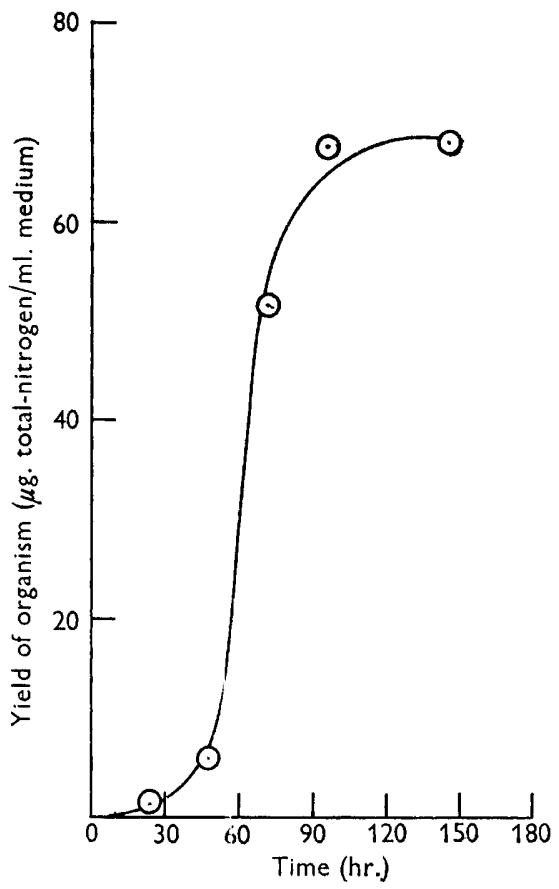

Fig. 1. Growth during the tenth serial subculture of the Wills strain of Actinomyces israelii at $37^{\circ}$ under liquid paraffin seals in $2 \mathrm{ml}$. volumes of medium D (Table 3).

The possibility remained that the anino acid complement of medium $\mathrm{D}$ might be still further decreased, or that ammonium sulphate could be eliminated as shown by Christie \& Porteous (1962a) for media containing twenty amino acids. Since chromatographic analysis of medium $\mathrm{CP} 1$ did not distinguish between assimilation of leucine and of isoleucine by Actinomyces israelii it was decided to test the requirement for these two amino acids and for ammonium sulphate. Eight media were prepared (Table 5); the basal medium in each case consisted of items 1, 2, 3 and 4 of Table 1 together with the L-amino acids serine, cysteine, lysine, glutamic acid and tryptophan and the growth factors inositol, riboflavin, nicotinic acid, pyridoxal and biotin, at the concentrations given in Table 1. The inoculum suspension of colonies was prepared in medium D (Table 3) in the manner described under Methods. Replicate tubes of each of the media D-M inclusive (Table 5) were uniformly inoculated and growth followed by visual scoring and by determining the 
changes in titratable acidity and changes in the $\mathrm{pH}$ value of the media during growth. Some growth was obtained in the first culture in all eight media. Very little growth occurred in a second serial culture in media G, L and M and virtually none in media $\mathbf{H}, \mathbf{I}, \mathbf{J}$, and $\mathbf{K}$; only in medium $\mathbf{D}$ was good growth obtained in this subculture. In a third serial culture very little growth was obtained in any medium except medium D.

\section{Table 5. The composition of eight test media}

For composition of the basal medium, see the text.

\begin{tabular}{cccc} 
& \multicolumn{3}{c}{ Additions to basal medium } \\
\cline { 2 - 5 } Medium & $\begin{array}{c}\text { Leucine } \\
(\mathbf{2 0 0} \mathrm{mg} . / 1 .)\end{array}$ & $\begin{array}{c}\text { Isoleucine } \\
(200 \mathrm{mg} . / \mathrm{l} .)\end{array}$ & $\begin{array}{c}\left(\mathrm{NH}_{4}\right)_{2} \mathrm{SO}_{4} \\
(200 \mathrm{mg} . / \mathrm{l})\end{array}$ \\
$\mathbf{D}$ (Table 3) & + & + & + \\
$\mathbf{G}$ & + & + & - \\
$\mathbf{H}$ & - & + & + \\
$\mathbf{I}$ & - & + & - \\
$\mathbf{J}$ & + & - & + \\
$\mathbf{K}$ & + & - & - \\
$\mathbf{L}$ & - & - & + \\
$\mathbf{M}$ & - & - & -
\end{tabular}

\section{DISCUSSION}

Experiments culminating in the results shown in Fig. 1 demonstrated that medium CP 2 (Table 1) containing twenty amino acids and five growth factors could be further simplified in respect of its amino acid content to give medium D (Table 3) containing only seven amino acids (serine, cysteine, lysine, glutamic acid, leucine, isoleucine, tryptophan) while still sustaining vigorous growth of the Wills strain of Actinomyces israelii in serial subculture. Further experiments showed that the leucine, isoleucine and ammonium sulphate were all essential components of medium D (Tables 3 and 5). Christie \& Porteous (1962a) demonstrated that cysteine and tryptophan were essential nutrients for this organism. It remains to be shown that serine, lysine and glutamic acid were also essential components of medium $\mathrm{D}$; experiments to elucidate this point are planned, but these three amino acids were amongst the group of amino acids, including the essential amino acid cysteine which was assimilated to the greatest extent during growth of $A$. israelii in a complete amino acid medium (Table 2). It seems probable therefore that the seven amino acids of medium D (Table 3) constitute the minimal amino aci d requirement of the Wills strain of $A$. israelii, provided an inor ganic source of nitrogen (ammonium sulphate) is also present in the medium; medium $\mathbf{D}$ also contained the minimal growth factor requirements for this organism (Christie \& Porteous, 1962 $b$ ) and therefore represents the simplest chemically defined mediu $\mathrm{m}$ yet devised for the growth of $A$. israelii.

In comparative experiments, media $\mathrm{A}, \mathrm{B}, \mathrm{C}$ and $\mathrm{D}$ (Table 3 ) gave similar yiel $\mathrm{d}$ of Actinomyces israelii and the organism grew at similar rates in the four media. The growth obtained ('Table 4) in media A and B confirmed the observation of Christie \& Porteous (1962 $a$ ) that purines and pyrimidines were not required by the Wills strain of $A$. israelii when grown in a complete amino acid medium con tainin 
sixteen growth factors (Tables 1 and 3); comparison of the growth of $A$. israelii in media $B$ and $C$ (Tables 3 and 4 ) showed that the purines and pyrimidines were not required for good growth even when the growth factor complement of the complete amino acid medium was decreased from sixteen to five components.

It will be noted, however, that purine and pyrimidine bases inhibited growth of the Wills strain of Actinomyces israelii in certain circumstances, namely when the amino acid complement and the growth factor complement of medium CP1 were simultaneously decreased in a specified manner (Table 3 ). Thus medium $\mathrm{F}$ gave poor growth while medium B and medium D gave good growth of $A$. israelii (Table 4); medium $\mathbf{F}$ and medium $\mathbf{D}$ both contained the same seven amino acids and the same five growth factors but mediurn $\mathbf{F}$ contained purine and pyrimidine bases in addition; medium $\mathbf{F}$ and medium $\mathbf{B}$ both contained the same purine and pyrimidine bases but differed in that the former contained seven amino acids and five growth factors while the latter contained twenty amino acids and sixteen growth factors (Table 3). Christie \& Porteous (unpublished) found that addition of adenine and thymine to medium CP2 (Table 1 ) resulted in less vigorous growth of the same strain of $\boldsymbol{A}$. israelii; this last observation, together with the present results, suggests that it was the absence of one or more of a group of certain growth factors, rather than the absence of one or more of a group of certain amino acids from medium $\mathbf{F}$ (Table 3 ) which elicited the inhibitory effect of the bases on growth of the organism. If this deduction is correct, addition of purine and pyrimidine bases to medium $\mathrm{C}$ (Table 3 ) should inhibit growth of the Wills strain of $A$. israelii; this is to be tested in experiments in progress.

Medium $\mathbf{E}$ differed from medium $\mathbf{A}$ only in that the latter contained twenty instead of seven amino acids (Table 3); since good growth was obtained in Medium A and poor growth in medium $\mathrm{E}$ (Table 4) it might seem that medium $\mathrm{E}$ was deficient in amino acids. On the other hand, medium $\mathbf{E}$ differed from medium $\mathbf{D}$ only in that the latter contained five instead of sixteen growth factors (Table 3); since medium D gave good growth of the organism, comparable with that obtained in medium $\mathbf{A}$, it is apparent that the poor cell yields and growth rates obtained in medium $\mathbf{E}$ (Table 4) were in fact due to some antagonistic effect on growth of one or more of the 'growth factors' present in medium $\mathbf{E}$ but absent from medium $\mathrm{D}$ (Tables 1 and 3). This antagonistic effect only became manifest when the twenty amino acids of medium $\mathbf{A}$ were decreased in number to the seven present in medium $\mathrm{E}$ (Tables 1 and 3).

Christie (unpublished) failed to obtain consistent growth of the Wills strain of A. israelii in medium CP1 (Table 1) modified to contain only the seven amino acids listed in Table 3 instead of the original complement of twenty amino acids; the present results suggest that this failure was due to the presence of inhibitory 'growth factors' in the simplified medium and/or to the absence of ammonium sulphate from the simplified medium.

These observed inhibitions of growth of Actinomyces israelii by 'growth factors' and by certain purines and pyrimidines in specified circumstances lend support to the supposition of Erikson \& Porteous (1953) that reported failures to obtain consistent growth of $\boldsymbol{A}$. israelii, particularly in complex and undefined media, may be due as much to the presence of growth inhibitors in the medium as to the absence of required nutrients. It is apparent (see also Christie \& Porteous, 1962 $a, b$ ) that 
Actinomyces israelii is a fastidious organism because it, like many other organisms, requires a carefully balanced medium rather than one containing excessive quantities or a wide variety of nutrients.

We thank the Department of Scientific and Industrial Research for a Research Studentship awarded to one of us (H.A.K.).

\section{REFERENCES}

Borssonas, R. A. (1950). Séparation rapide des acides aminés par chromatographie ascendante bidimensionelle sur papier. Helv. chim. acta, 33, 1966.

Christie, A. O. \& Porteous, J. W. (1960). A technique for obtaining uniform inocula of Actinomyces israelii. J. gen. Microbiol. 23, 261.

Christie, A. O. \& Porteous, J. W. (1962a) The cultivation of a single strain of Actinomyces israelii in a simplified and chemically defined medium. J. gen. Microbiol. (in the Press).

Christie, A. O. \& Porteous, J. W. (1962b). The growth factor requirements of the Wills strain of Actinomyces israelii growing in a chemically defined medium. J. gen. Microbiol. (in the Press).

Consden, R., Gordon, A. H. \& Martin, A. J. P. (1944). Qualitative analysis of proteins: a partition chromatographic method using paper. Biochem. J. 38, 224.

Dent, C. E. (1947). The amino-aciduria in Fanconi syndrome. A study making extensive use of techniques based on paper partition chromatography. Biochem. J. 41, 240.

Erikson, D. \& Porteous, J. W. (1953). The cultivation of Actinomyces israelii in a progressively less complex medium. J. gen. Microbiol. 8, 464.

FowDEN, L. (1951). The quantitative recovery and colorimetric estimation of amino-acids separated by paper chromatography. Biochem. J. 48, 327.

Kornberg, L. H. \& PAtey, W. E. (1957). Quantitative determination of 0.5-5 $\mu \mathrm{g}$. of amino acid nitrogen on paper chromatograms and in solution. Biochim. biophys. Acta, $25,189$.

Levvy, A. L. \& Chung, D. (1953). Two dimensional chromatography of amino acids on buffered papers. Analyt. Chem. 25, 396.

Yемм, E. W. \& Cocking, E. C. (1955). The determination of amino acids with ninhydrin. Analyst, 80, 209. 